\title{
Financial Deepening and Sustained Economic Growth in Nigeria: What Nonlinear Models Reveal
}

\author{
Ebere Ume Kalu ${ }^{1}$, Chinwe R. Okoyeuzu¹, Elizabeth U. Okechukwu² and \\ Wilfred Isioma Ukpere ${ }^{3, *}$
}

\author{
${ }^{1}$ University of Nigeria, Nsukka, Nigeria \\ ${ }^{2}$ Enugu State University of Science and Technology, Enugu State, Nigeria \\ ${ }^{3}$ Department of Industrial Psychology and People Management, Johannesburg Business School, College of \\ Business \& Economic, University of Johannesburg, South Africa
}

\begin{abstract}
Motivated by the desire to expose a possible nonlinearity and non-proportionality in linking financial deepening and economic growth, we investigated the finance-growth nexus from a linear and nonlinear perspective using dataset from Nigeria for 1981: Q1 to 2017: Q4. Using the Autoregressive Distributed Lag (ARDL) and Nonlinear Autoregressive distributed Lag (NARDL) models, and it was found that economic growth tends to adjust nonlinearly to financial deepening than it does linearly. This is expected to guide policy makers towards ensuring that the linearity and nonlinearity polarity of the finance-growth nexus are always factored-in while formulating policies relative to driving sustained growth through financial deepening.
\end{abstract}

Keywords: ARDL, NARDL, Financial Deepening, and Economic Growth.

\section{INTRODUCTION}

Associating the penetration of a financial system on economic growth has over some decades been on the front burner. As it is well established, financial system is made up of institutions, markets, individuals, regulators and all those who play in fund intermediation. The most important focus has been on depth of the market and banks/institutions. It is quite admissible that financial systems are different in terms of depth, and several reasons have been adduced for these disparities. Dahou, Omar \& Pfister (2009) identified inadequate regulatory regimes, sub-optimal bank intermedition services, weak financial markets, and lack of innovative financial instruments as impediments to financial development and deepening of the financial markets in developing economies. This overly accounts for the differences between developed and developing economies financial systems.

In terms of measurement and investigation of the financial depth-growth nexus, there have been a predominant use of regression, cointegration and other models of linear nature. Studies such as Khan \& Senhadji (2000); Ndebbio (2004); Singh \& Huang (2011) and Barajas, Chami, \& Yousefi (2013), focused on regional or global scale, while Nzotta \& Okereke (2009); Onwumere, Ibe, Ozoh, \& Mounanu (2012); Balago (2014); Aye (2015) and Kalu, Nkwor, \& Onwumere (2015) concentrated on Nigeria. However, almost all the studies employed empirical methods with linearity assumption. It is almost a general consensus

*Address correspondence to this author at the Department of Industrial Psychology and People Management, Johannesburg Business School, College of Business \& Economic, University of Johannesburg, South Africa; Tel: +27-735295587; Fax: +27-11-5593942; E-mail: wiukpere@uj.ac.za that economic growth is a positive function of financial deepening. A commonly asked question however, becomes whether the conclusions are based on proof of evidence or the power of test.

Nigeria as a country has a vast financial system that should act as an engine of growth for the multi-sectoral economy. Growth has been abysmal and financing has been largely blamed for the poor level of growth over the years. It becomes imperative to reexamine the finance-growth nexus with the view to appraising this relationship with the aim of determining the elasticity and direction of growth in relation to the depth of the financial system. Curiously, there is also the need to apply the right collection of estimation technique hence the combination of the linear and non-linear models given that the nature of the nexus will arguably determine the right and workable policy interventions.

\subsection{Problem Statement}

The finance-growth nexus has always been approached from the linearity perspective. Though many conclusions have been drawn on this basis, it is however obvious that every relationship cannot be linear. It is not statistically tenable to draw conclusions about a phenomenon on the basis of a single strand of test for inference purposes (Gunst and Mason, 1980: 167-206). Following Nam, Pyun and Arize, (2002), it makes both research and intuitive sense to have a conclusion on this nexus premised on the non-linear models, which somewhat have favorable consideration over their linear counterparts. This is made more expedient by the fact that most economic and financial time series are typically skewed and leptokurtic (Brooks, 2014). The oscillatory movement and spikes associated with such data sets make linear models less 
adequate for a conclusive estimation. In sum, this study addresses a problem of exposing the likely defect in the estimation pattern of previous conclusions drawn on the finance-growth nexus with a particular focus on the Nigerian economy.

\subsection{Significance of the Study}

This study is intended to look at the flipside of what prior authors have done, that is, using nonlinear models to examine this relationship. It is an effort directed at questioning the assumed linearity of financial deepening and economic growth relationship. Acknowledging the significance of the findings of this study, we are of the view that the study will support policy-makers and market practitioners alike. One of the significance of the study is that policy makers will discover whether the reactionary disposition of growth to variations in financial deepening indicators follows a linear or nonlinear direction. For the market participants, they may be fascinated in recognizing how changes in financial deepening indicators may affect macroeconomic conditions with a possible transmission effect on the activities in the fiancial market. The results of this study can be useful for general conclusions regarding most African economies. Furthermore, literature will be enhanced due to the evidence presented from our findings. The outcome of this study provides a confirmation to previous findings given the novelty of the techniques suggested in this study.

\subsection{Contributions of the Study}

A study such as this should have several values added, one of which is to provide new evidence that will show that economic growth, can in variation to conclusions by prior authors' nonlinearity respond to financial deepening. This will be shown in their short and long run forms. The second value-added of this work is pointing out that the knowledge of the degree to which economic growth has affected financial deepening indicators is important because this relationship can appreciably drive or retard advancements in the financial system.

The value addition following the earlier mentioned is that we check for the possibility that the finance-growth nexus can be nonlinear. Owing to this, a recent technique by Shin, Yu, and Greenwood-Nimmo (2014) was employed. This model has scarcely been used on Nigerian data. This technique permits regressors with the partial sum of positive and negative changes to be engaged, through the positive and negative partial sum decompositions of the regressors, which simultaneously tests the long and short-run nonlinearities. The Nonlinear Autoregressive distributed technique is adequate because it is likely that the same effect may not be obtainable from a positive or negative variation in one variable

Nigeria, being one of the largest economy in Africa, became a strong reason for selecting the country for this study. Our findings are expected to provide empirical evidence for policy-making in financial system development, which impacts positively on sustainable economic growth. A contribution towards literature enrichment in financial systems interactions, especially in developing economies is a strong part of this work.

\subsection{Structure of the Paper}

We structured the remnant of this work as follows: In section two, a review of related literature is presented while section three presents the methodology. The last but one section discusses the result, and the study is concluded in the fifth section.

\section{LITERATURE REVIEW}

\subsection{Brief Empirical Review}

Discourse on financial development and economic growth relationship on country specific levels abounds. The proliferation of such studies has been aimed at showing the finance-growth forces as they apply in economies in their distinctive characteristics (Khan \& Senhadji, 2000). Studies such as Khan and Senhadji (2000), Singh and Haung (2011) found positive links between finance and growth in cross country platforms with varied degrees of influence in terms of the indicators.

Barajas et al. (2013), Nzotta \& Okereke (2009) and Balago (2014) using more robust estimation techniques such as Generalised Method of Moments (GMM) dynamic panel estimation, 2-Stage least squares and OLS method combined with Vector Error Correction Model had mixed results. Barajas (2013) hold that positive links in finance-growth nexus with their findings supporting strong heterogeneity made possible by regional characteristics and income level. Nzotta and Okereke (2009) and Balago (2014) similarly found a positive link between financial system development and economic growth. Kalu et al. (2015) adopted the traditional Engel-Granger two-way co-integration model in investigating the growth-financial depth in Nigeria. They found a long run association between the financial depth and the economic growth with a reasonably sized and rightly signed error correction representation; suggesting a strong positive link in the finance-growth interplay.

All these studies adopted estimation techniques and approaches that are founded on linearity assumptions 
such as the OLS and its concomitances, linear cointegration of both single and system equation framework and others in this similitude. This study departs from this verge by revealing the possible drift in previously drawn conclusions if/when nonlinear models are adopted.

\subsection{Theoretical Considerations}

Prominent Financial development and growth theoretical linkage abound. There is the growth/financial efficiency hypothesis of Grgorio \& Guidotti, (1995) and productive investments theory of Dahou, Omar, \& Pfister, (2009) anchored on effective allocation of the accumulate capital mobilized in the financial markets.

This study draws from the prominent McKinnon (1973) complementarity hypothesis and Shaw (1973) debt intermediation theory. McKinnon-Shaw framework show that repressed financial markets result in disincentive to savings which has negative impacts on capital accumulation vis-à-vis capital allocation, investment and economic growth. These theories have been tested in a manner that the depth or shallowness of the financial intermediation platform can be of essence to economic growth through the demand and supply channels (see Barajas et al. 2013, Greenwood \& Smith 1997, McKinnon, 1973; Shaw, 1973 and Robinson, 1952). Moreover, the conclusion for economies on the basis of supply leading and demand following hypothesis or the flipside has also been stressed in prior studies.

The theoretical leaning of this study however modifies those of prior authors by questioning the pervading linearity assumption of this relationship under study with the sole aim of investigating the possibility of non-proportionality and nonlinearity in the finance-growth nexus with the Nigerian economy as the base.

\section{RESEARCH METHODOLOGY}

The study will adopt a wholly empirical approach using data sets drawn from the Nigerian economic environment covering the period 1981:Q1 to 2017:Q4. Financial deepening indicators such as Ratio of Credit to the Private Sector to Economic Growth (CPS/GDP) and Ratio of Broad Money Supply to Economic Growth (M2/GDP) will be presented as the regressors and the proxy for Economic Growth (GDP growth rate) is used as the explained variable. The use of Nigerian data contributes to a better understanding of the financial forces in an emerging economy whose structure and institutional characteristics are different from the developed ones.
One of our expectations is that a fresh line of evidence on the possible nonlinear association between financial deepening and economic growth will be provided. Moreover, it will add to the discourse and debate on the form and style of the Financial Deepening/GDP nexus thereby enriching the literature in this important area of finance and economics. Essentially, results from this study will be a guide to policy makers. Efforts directed towards the development of the financial system will be in a manner that will strike a balance between the linearity assumption and the nonlinearity assumption of the economic growth and financial deepening linkage.

Our empirical estimations are guided by three key considerations: in the first place, the expansion in the knowledge of time series and allied application into diverse disciplines permits one to analyze economic/financial relationships in ways not previously thought possible. On this premise, the first is to focus on exposing the statistical and stationarity properties of the time series by looking at the descriptive statistics, the correlational matrices and the unit root properties of the data. These tests are important guides in choosing the right estimation technique, appropriate model specification, and help us to avoid specification bias. Given the fact that the traditional unit root tests are apparently powerless in the face of structural break, innovational, additive and other forms of outliers, we employ traditional unit root test side by side with structural break consistent unit root tests. The traditional Dickey and Fueller (1979) specifications, Zivot and Andrews (1992) break endogenized tests as well as other structural break tests that exogenously select the break date. Secondly, we estimate the baseline ARDL and test for cointegration following the Pesaran, Shin and Smith (2001) framework which is largely focused on linearity. The nonlinear baseline tests are conducted by using the partial sums generated for all the variables following an econometric process and the nonlinear cointegration test about this relation is done by using the new Nonlinear Autoregressive distributed Lag (NARDL) model by Shin, $\mathrm{Yu}$, and Mimmom-Greenwood (2014). Thirdly, we estimate the speed of adjustment of economic growth to changes in financial deepening indicator following the ARDL and NARDL framework. Knowing how quickly economic growth responds to changes in the explanatory variables is essential for understanding the dynamics of the financial deepening-growth nexus; from the point of view of policy makers. Overly, the whole estimations are subjected to diagnostic tests in a manner that ensures that the classical assumptions underlying the econometric techniques are not violated. 


\subsection{Data Source}

It is from the Central Bank of Nigeria Statistical Bulletin 2016 that the data for the study was obtained. Time series data from 1981:Q1 to 2016:Q4.were selected. One of the key sources of data is the central bank of Nigeria (CBN). This makes our source of data a credible option. Due to the fact that the data sets have regular time-ordering/frequency, they are time series. Some of the variables are scaled; that is, one used as a percentage of the other. Moreover, the natural logarithm of the unscaled variables was used while the scaled variables were used in their level form.

\subsection{Model Specification}

The research centers on instituting a link between economic growth and financial deepening indicators. Remarkably, growth of any economy can be catalyzed by the depth of the financial system but in variance to prior authors, this study models not just the short run relationship but presents a cointegration analyses, error correction representation and dynamic profile analysis. This study strategically departs from prior authors by questioning the linearity assumption that pervades the literature in Economic growth and financial deepening nexus. This implies that fresh evidence using the nonlinear ARDL is sought by this study to add a girth to the existing literature in this novel area.

The baseline relationship to be studied is as shown in equation:

$$
L G D P_{t}=\delta_{0}+\delta_{1} \mathrm{LM}_{2} \mathrm{GDP}_{t}+\delta_{2} \mathrm{CPSGDP}_{t}+\varepsilon \mathrm{t} \quad \text { eq. } 1
$$

LGDP is the natural logarithms of GDP, a representative for economic growth. M2GDP and CPSGDP are scaled variables which Broad Money denominated by GDP and Credit to the Private Sector scaled by GDP; these two are the core measures of financial deepening. While M2GDP is for institutional depth, CPSGDP shows market depth, while $\varepsilon t$ is the residual or error term.

\section{The Stationarity Properties of the Series}

To expose the unit root properties of the series under study, variants of traditional and structural break consistent unit root tests were used. The Augmented Dickey Fueller sequential procedure for unit root test that uses the whole sample is carried out using the following regression model with a design of selecting the break date endogenously.

$$
\begin{array}{r}
\Delta y_{t}=P y_{t-1}+\mu+\underset{p}{\alpha \vartheta_{t}\left(t_{\text {used }}\right)+\lambda t} \\
+\sum_{i=1}^{\infty} \alpha_{i} \Delta y_{t-i}+\mu_{t}
\end{array}
$$

Where $\left(t_{\text {used }}\right)=\mathrm{Tb} / \mathrm{T}$ which is the trimmed sample. $\vartheta_{t}\left(t_{\text {used }}\right)$ allows for the break which can either be in the level where it is equal to 1 when $t>t_{\text {used }}$ and 0 if otherwise. It can also break in the deterministic trend where $\vartheta_{t}\left(t_{\text {used }}\right)=t-t_{\text {used }}$ if $t>t_{\text {used }}$ and 0 if otherwise.

For the purposes of carrying out this structural-break-consistent unit root test, firstly, the standard Dickey-Fueller test is done. Secondly, the minimum DF statistic $t_{D F}^{\min }$ is obtained, and the maximum DF statistic $t_{D F}^{\max }$ will be obtained and the difference between the two ( $\max$ and $\mathrm{min}$ ) will be taken finally. The break date selection processes and trimming is performed to remove endpoint values from being considered as break dates. To capture the nature of the change (outlier) that induces the structural break, that is, whether it is gradual (innovational outlier) or rapid (additive outlier); variants of the two unit root test are done following the form presented below:

\section{Additive Outlier Model}

$\tilde{y}_{\mathrm{t}}=\sum_{j=0}^{k} \mathrm{~W}_{\mathrm{t}} \mathrm{D}(\mathrm{Tb})_{\mathrm{t}-1}+\alpha \tilde{y}_{\mathrm{t}-1}+\sum \mathrm{cj} \Delta \mathrm{y}_{\mathrm{t}-\mathrm{j}}+\varepsilon_{\mathrm{t}} \quad$ eq. 3

Where: $\tilde{y}_{\mathrm{t}}=\mathrm{a}$ detrended series of $\mathrm{Y}$ and $Y_{t}={ }_{\gamma}+\partial D \mu_{t}+\tilde{y}_{t}$

\section{Innovation Outlier Model}

$Y_{t}={ }_{\gamma}+\partial D \mu_{t}+\theta \mathrm{D}(T b)_{t}+\alpha \tilde{y}_{\mathrm{t}-1}+$

$\sum_{j=1}^{k} \mathrm{cj} \Delta \mathrm{y}_{\mathrm{t}-\mathrm{j}}+\varepsilon_{\mathrm{t}}$

eq. 4

The structural break test as proposed by Zivot and Andrews (1992) which also has a process for endogenizing the break date is used as a robustness check on the above unit root processes. This follows the three equations as propounded by Zivot and Andrews (1992):

$$
\begin{aligned}
& \Delta y_{t}=c+\Delta y_{t-1}+\beta_{t}+\gamma D T_{t}+\sum_{j=i}^{k} d_{j} \Delta y_{t-j}+ \\
& \varepsilon_{t} \ldots \ldots \ldots \ldots \ldots \ldots \ldots \ldots \ldots \text {...................... } \\
& \Delta y_{t}=c+\Delta y_{t-1}+\beta_{t}+\theta D T_{t}+\sum_{j=i}^{k} d_{j} \Delta y_{t-j}+ \\
& \varepsilon_{t} \ldots \ldots \ldots \ldots \ldots \ldots \ldots \ldots \ldots \ldots \text {................... Model } 2
\end{aligned}
$$

Where: $D U t$ is an indicator dummy variable for a mean shift occurring at each possible break-date (TB) while $D T t$ is corresponding trend shift variable.

\subsection{The ARDL Method}

This study adopts the ARDL technique due to its numerous benefits over others. This according to Arize (2017) includes:

- It is efficient in the face of small samples 
- It is a dynamic model hence less prone to autocorrelation and other deficiencies common with other regression models

- Its ability to make a linear combination of variables with different orders of integration, [I (0), I(1)].

Following Pesaran and Shin (2001) as cited in Arize, Kalu and Nkwor (2018) the formal augmented-ARDL model is defined as

$$
\begin{gathered}
\phi(L, p) y_{t}=\sum_{i=1}^{k} \beta_{i}(L, p) x_{i t}+\delta^{\prime} w_{t}+\mu_{t} \quad \text { eq. } 8 \\
\text { Where: } \phi(L, p)=1-\phi_{1} L-\phi_{2} L^{2}-\cdots-\phi_{p} L^{p} \text { and } \\
\beta_{i}(L, p)=\beta_{i 1}+\beta_{i 1} L+\beta_{i 2}+\cdots+\beta_{i q i} L_{i}^{q} i=1,2, \ldots, k
\end{gathered}
$$

and where $\mathrm{L}$ is a lag operator and $w_{t}$ is an $s \times 1$ vector of deterministic variables such as the intercept term, dummy variables, time trends or exogenous I(1) variables with fixed lags. SBC information criteria were generated so as to select the optimal model. This was achieved automatically by the estimation software following the form of equation 7 as specified below:

$$
B I C=\ln (n) K-2 \ln (\hat{\mathcal{L}})
$$

Where: $\mathrm{n}=$ the number of data points in $\mathrm{x}$, the number of observations, or equivalently, the sample size;

$\mathrm{k}=$ the number of free parameters to be estimated. If the estimated model is a linear regression, $k$ is the number of regressors, including the intercept;

$\hat{\mathcal{L}}=$ the maximized value of the likelihood function for the estimated model $M$ given as $\hat{\mathcal{L}}=p\left(\frac{x}{\widetilde{\theta}}, \mathcal{M}\right)$

\subsection{Cointegration Test (Bound Test)}

In carrying out the bound test, the procedure as prescribed by Pesaran and Shin (2001) in the ARDL framework is followed. Accordingly, critical values using two sets value, lower and the upper bound was chosen. I(1) for the upper band and I(0) for the lower band. The decision guide is as contained in the Table 1 below:

\subsection{Error Correction Representation}

Once the existence of cointegration in the specified models has been established, error correction representations and long run coefficients are estimated following the form specified in the equations below:

$$
\begin{aligned}
& \Delta L G D P_{t}=\pi_{p}+\sum_{i=1}^{k} \delta_{i p} \Delta L G D P_{t-i}+\sum_{i=1}^{k 1} \tau_{i p} \Delta C P S G D P_{t-i} \\
& +\sum_{i=1}^{k 2} \theta_{i p} \Delta C P S_{t-i}+\sum_{i=1}^{k 3} \sigma_{i p} \Delta L M 2_{t-i}+\sum_{i=1}^{k 4} \delta_{i p} \Delta M 2 G D P_{t-i}+ \\
& \varpi_{1 p} L G D P_{t-1}+\varpi_{2 p} C P S G D P_{t-1}+\varpi_{3 p} L C P S_{t-1}+\varpi_{4 p} L M 2_{t-1} \\
& +\varpi_{5 p} M 2 G D P_{t-1}+\xi_{1 t}
\end{aligned}
$$

Shin, Yu, and Greenwood-Nimmo (2014) developed a model to study the potential nonlinear and asymmetric effects in the long run and in the short run. In most time series estimation, it is assumed that a linear combination of $y_{t}$ and $x_{t}$ will result in a symmetric adjustment in the long and the short run. However, there will be cases where the relationship between $y_{t}$ and $x_{t}$ becomes non-linear and $x$ begins to impact $y$ asymmetrically. This makes a justification for the NARDL model which is more flexible with the capacity to relax the expectations of ECM regarding the properties of time series variables, in which they are required to be integrated in the same order. Precisely, the NARDL method is an extension of the linear ARDL. It begins by decomposing $x_{t}$ into its positive and negative partial sums as follow:

$x_{t}=x_{0}+x_{t}^{+}+x_{t}^{-}$

where, $x_{t}^{+}$and $x_{t}^{-}$are partial sum processes of positive and negative changes in $x_{1}$ :

$x_{t}^{+}=\sum_{j=1}^{t} \Delta R_{j}^{+}=\sum_{j=1}^{t} \max \left(\Delta R_{j}, o\right)$,

and

$x_{t}^{-}=\sum_{j=1}^{t} \Delta R_{j}^{-}=\sum_{j=1}^{t} \min \left(\Delta R_{j}, o\right)$

Following Shin, Yu, and Greenwood-Nimmo (2014), the non-linear asymmetric co-integrating regression is estimated to arrive at the long run coefficient associated with the positive and negative changes.

Shin, Yu and Greenwood-Nimmo (2014) exposed that by substituting in the ARDL $(p, q)$ Equation, we find the following non-linear asymmetric conditional ARDL:

Table 1: Decision Rules for the Bound Tests Process

\begin{tabular}{|c|c|c|}
\hline State & Inference \\
\hline \hline F-stat larger than the lower and upper bound & $\begin{array}{c}\text { Fail to accept the null hypothesis of no long } \\
\text { run relationship }\end{array}$ & $\begin{array}{c}\text { A cointegrating relationship } \\
\text { exists }\end{array}$ \\
\hline F-stat less than the lower and upper bound & $\begin{array}{c}\text { Do not reject the null hypothesis of no long run } \\
\text { relationship }\end{array}$ \\
\hline $\begin{array}{c}\text { F-stat at the chosen level of significance falls within the lower } \\
\text { and upper bound }\end{array}$ & $\begin{array}{c}\text { Results is indecisive } \\
\text { relationship exists }\end{array}$ \\
\hline
\end{tabular}


$\Delta y_{t}=c_{0}+\rho y_{t-1}+\theta^{+} x_{t-1}^{+}+\theta^{-} x_{t-1}^{-}+\vartheta z_{t}+\sum_{j=1}^{p-1} \Upsilon_{j} \Delta y_{t-j}$ $+\sum_{j=0}^{q-1}\left(\varphi_{j}^{+} x \Delta x_{t-j}^{+}+\varphi_{j}^{-} x \Delta x_{t-j}^{-}\right)+\varepsilon_{t}$

eq. 16

Following Pesaran et al. (2001), as contained in the steps modelled in Arize (2017), the error correction form could appear thus:

$\Delta y_{t}=\rho \xi_{t-1}+\sum_{j=1}^{p-1} \Upsilon_{j} \Delta y_{t-j}+\sum_{j=0}^{q-1}\left(\dot{\varphi}_{j}^{+} x \Delta x_{t-j}^{+}+\right.$ $\left.\varphi_{j}^{-} x \Delta x_{t-j}^{-}\right)+\varepsilon_{t}$

with $\varepsilon_{t}$ showing the nonlinear ECM term associated with the asymmetric long-run parameters.

\section{RESULTS}

From the stationarity properties of the series, following the different test techniques, the results shown in Panel A there are differences in the manner the variable are integrated., that is, a combination of $\mathrm{I}(0)$ and $\mathrm{I}(1)$ variables. This fits our specification of the ARDL model and most importantly, there is no I (2). The results show the break dates as endogenously selected by the estimation methods. For the economic growth-related variables, the break dates were predominantly in the 1990's. A look at the Nigerian economy within the period shows that these were periods of mass instability and economic vicissitudes caused by the military rule known for poor fiscal discipline, budgetary inadequacies, poor records of growth and development, unimaginable public-sector misappropriation and corruption.

For the credit and money related variables, the break dates were predominantly in the 2000's. One of the most pronounced banking sector reforms that Nigeria has ever witnessed took place between $2004 / 2005$. This was characterized by massive bank recapitalization and the collapse of several banks. Even on a global scale, the 2007/2008 was the period of the global financial crises. The structural break dates shown by the tests reasonably show the outliers created by the banking reforms and global financial crises around the periods indicated.

Our basic descriptive statistics is presented in Panel B. These are the mean, median, standard deviation, minimum and maximum. The excess kurtosis as well

Table 2: Summary of Data

\section{Panel A: Unit Root Tests Results}

\begin{tabular}{|c|c|c|c|c|c|c|c|c|c|c|c|c|}
\hline \multirow[t]{2}{*}{ Variables } & \multicolumn{3}{|c|}{$\begin{array}{c}\text { Traditional ADF } \\
\text { (Trend and Intercept) }\end{array}$} & \multicolumn{3}{|c|}{$\begin{array}{l}\text { Break with Innovation Outlier } \\
\text { (Trend and Intercept) }\end{array}$} & \multicolumn{3}{|c|}{$\begin{array}{l}\text { Break with Additive Outlier } \\
\text { (Trend and Intercept) }\end{array}$} & \multicolumn{3}{|c|}{$\begin{array}{c}\text { Zivot and Andrews Unit Root } \\
\text { Test } \\
\text { (Trend and Intercept) }\end{array}$} \\
\hline & $\begin{array}{l}\text { ADF } \\
\text { Stat }\end{array}$ & $\begin{array}{l}\text { Critical } \\
\text { Value } \\
(0.05)\end{array}$ & $\begin{array}{c}\text { Order of } \\
\text { integration }\end{array}$ & $\begin{array}{l}\text { ADF } \\
\text { Stat }\end{array}$ & $\begin{array}{c}\text { Break } \\
\text { Date }\end{array}$ & $\begin{array}{l}\text { Order of } \\
\text { integration }\end{array}$ & $\begin{array}{l}\text { ADF } \\
\text { Stat }\end{array}$ & $\begin{array}{c}\text { Break } \\
\text { Date }\end{array}$ & $\begin{array}{c}\text { Order of } \\
\text { integration }\end{array}$ & $\begin{array}{l}\text { ZAU } \\
\text { Stat }\end{array}$ & $\begin{array}{c}\text { Break } \\
\text { Date }\end{array}$ & $\begin{array}{c}\text { Order of } \\
\text { integration }\end{array}$ \\
\hline CPSGDP & -4.98 & -3.54 & 1 & -7.99 & 2007 & 0 & -7.71 & 2007 & 1 & -7.53 & 2008 & 0 \\
\hline M2GDP & -5.15 & -3.54 & 1 & -5.53 & 2007 & 0 & -6.53 & 2008 & 1 & -5.75 & 2007 & 1 \\
\hline
\end{tabular}

\begin{tabular}{|c|c|c|c|}
\hline \multicolumn{4}{|l|}{ Panel B: Descriptive Statistics } \\
\hline Variable(s) & GDP & $M 2 G D P$ & CPSGDP \\
\hline Maximum & 11.53 & 21.29 & 20.77 \\
\hline Minimum & 4.98 & 9.15 & 5.92 \\
\hline Mean & 8.34 & 13.99 & 10.64 \\
\hline Std. Deviation & 2.27 & 3.86 & 5.22 \\
\hline Skewness & 1.49 & 1.69 & 1.88 \\
\hline Kurtosis -3 & .82 & 1.41 & 3.88 \\
\hline \multicolumn{4}{|l|}{ Panel C: Correlation Matrix } \\
\hline & GDP & $M 2 G D P$ & CPSGDP \\
\hline GDP & 1.0000 & - & - \\
\hline M2 & 0.9851 & - & - \\
\hline$M 2 G D P$ & 0.3749 & 1.0000 & - \\
\hline CPSGDP & 0.6012 & 0.9251 & 1.0000 \\
\hline CPS & 0.9847 & 0.4781 & 0.7076 \\
\hline
\end{tabular}


as the skewness, which are indicators of normality, are also contained in Panel B of Table 2. The correlation matrix contained in Panel $\mathrm{C}$ of Table 2 indicates that the variables share positive linear association of different strengths and degrees.

We next investigated the baseline relationship as shown in equation 2. Panel $A$ of Table 3 shows the ARDL and NARDL estimates. The first lag of economic growth is found to be a linear and nonlinear function of economic growth implying that lagged values of economic growth linearly and nonlinearly drives contemporaneous economic growth. For the explanatory variables, looking at the NARDL and ARDL variant of the estimates, CPSGDP is found to insignificantly affect economic growth linearly and nonlinearly. This is evidenced by the t-stat (1.07) and probability value that is less than the 0.05 level of significance. On the other hand, M2GDP is found to positively and significantly affect economic growth in both linear and nonlinear fashion. By this, it can be inferred that economic growth is positively driven linearly and nonlinearly by monetization ratio while financial access (CPSGDP) within the studied period exerted no significant impact on economic growth linearly and nonlinearly.

\section{Linear and Nonlinear Cointegration Bound Test}

Panel B of Table 3 shows the bound test for cointegration for both the linear and nonlinear model. In both instances, the F-stat is greater than the upper band as shown hence cointegration is found for the linear and nonlinear models respectively.

\section{Error Correction Representation}

Having detected cointegrating relationships in the linear and nonlinear models, we next investigate the error correction profile of the models. This is aimed at confirming adjustment to shocks and dynamics of the dependent variables to disequilibrium caused by the explanatory variables. Our results as reported in the lower rung of Panel B show that the error correction terms for the linear and nonlinear variants are rightly signed (negatively significant).

Table 3: Summary of NARDL and ARDL Estimates

\begin{tabular}{|c|c|c|}
\hline \multicolumn{3}{|c|}{ PANEL A: NARDL and ARDL Baseline Estimates } \\
\hline Variables & NARDL & ARDL \\
\hline $\operatorname{LGDP}(-1)$ & $\begin{array}{c}1.03 \\
199.73^{\star *}\end{array}$ & $\begin{array}{c}1.09 \\
5.727^{\star *}\end{array}$ \\
\hline CPSGDP $P^{-}$ & $\begin{array}{l}-0.03 \\
-1.07\end{array}$ & ------ \\
\hline CPSGDP $P^{+}$ & --- & $\begin{array}{c}0.009 \\
0.6365\end{array}$ \\
\hline $\operatorname{CPSGDP}(-1)^{-}$ & $\begin{array}{c}0.03 \\
1.346\end{array}$ & ----- \\
\hline $\operatorname{CPSGDP}(-3)^{+}$ & ----- & $\begin{array}{c}0.032 \\
2.608^{* *}\end{array}$ \\
\hline$M 2 G D P^{+}$ & ---- & $\begin{array}{c}0.056 \\
2.481^{* *}\end{array}$ \\
\hline$M 2 G D P^{-}$ & $\begin{array}{c}0.06 \\
2.68^{* *}\end{array}$ & -------- \\
\hline$M 2 G D P(-1)^{-}$ & $\begin{array}{c}0.08 \\
3.31^{\star *}\end{array}$ & \\
\hline \multicolumn{3}{|c|}{ Panel B- Bound Tests and Error Correction Representations: } \\
\hline F-Stat & $\begin{array}{c}25.79 \\
\mathrm{I}(0)=2.72, \mathrm{I}(1)=3.83\end{array}$ & $\begin{array}{c}4.897 \\
I(0)=3.88, I(1)=4.61\end{array}$ \\
\hline$E C M_{t-1}$ & $\begin{array}{c}-0.31 \\
-9.093^{* *}\end{array}$ & $\begin{array}{c}-0.27 \\
-4.717^{* *}\end{array}$ \\
\hline \multicolumn{3}{|c|}{ Panel C: Diagnostic Tests: } \\
\hline BG-LM F-stat & $1.26(0.3178)$ & $1.0329(0.3742)$ \\
\hline Het- BPG F-stat & $1.350(0.2728)$ & $0.6567(0.7378)$ \\
\hline RESET & $3.85(0.0755)$ & $3.77(0.0656)$ \\
\hline JB-Normality & $1.398(0.4970)$ & $0.869(0.647)$ \\
\hline
\end{tabular}

${ }^{* *}$ Significant at 0.05 level of significance. 
Interestingly, the nonlinear model shows a higher speed of adjustment $31 \%$ than the linear model of $27 \%$. This indicates that economic growth tends to adjustment nonlinearly at a greater pace to the shocks and dynamics of financial deepening than it does linearly. In the case of the nonlinear model, it takes about three years for any deviation from short run equilibrium to be restored in the long run, while it takes about four years for that to happen with the linear model. The adjustment speed is low, which may not be unconnected with the adjustment processes of the financial system to issues of deepening and economic growth. However, the oscillatory explosion can be predicted as the coefficients terms are between 0 and 1.

The estimates are shown to be reliable by the diagnostic tests reported in part $C$ of Table 3 . The absence of autocorrelation is shown by the Breusch and Godfrey (BG) Test for serial correlation. Also, the Breusch Pagan and Godfrey (BPG) test for heteroskedasticity also shows that in all the models, there are no cases of non-constant residual variance implying that all the models are found to be homoscedastic. In addition, the RESET test confirms that the model is stable and void of any specification error. The JB statistics evidently demonstrates that the residuals of both the linear and nonlinear models are normally distributed.

\section{CONCLUSION}

This study has examined the financial deepening-growth nexus from a linear and a nonlinear perspective. Motivated by the desire to unveil a possible nonlinearity in this relationship and adopting a combination of linear and nonlinear techniques in the empirical estimations from the perspective of short-run and long-run. Financial deepening indicators were found to positively and significantly affect the growth of the Nigerian economy, within the studied period consistent with the Supply-Leading hypothesis as proven by such authors as Greenwood \& Smith (1997), McKinnon, (1973); Shaw, (1973) and Robinson, (1952) even more recently by Nzotta \& Okereke (2009), Barajas et al. (2013), Balago (2014) and Kalu, Nkwor and Onwumere (2015).

In a very noticeable departure from prior authors, a strong evidence was uncovered in support of non-proportional and nonlinear linkage of financial deepening to economic growth. More strikingly, it was uncovered that economic growth nonlinearly adjusts at a faster rate to financial deepening than it does linearly. This finding questions the veracity of the position previously held in literature on the finance-growth nexus and therefore posits that previous findings may have been influenced by the limitations of the estimation methods employed by those authors. Economic and financial crises, wars, insurgency, extreme events, geopolitical tensions, cyclical fluctuations, policy instability and summersault, complexity of financial system, globalization and even the form of regulatory architecture can induce nonlinearity in time series relationships and dispositions (Atil, Lahiani and Nguyen, 2014). Given that these are glaring features of most developing economies, including Nigeria, arriving at a conclusion of nonlinearity in the finance-growth nexus is obviously not surprising. What is surprising however, is the sparseness of studies that have explored this dimension of the finance-growth linkage. This obviously becomes a key addition to literature made by this study.

Considering the key role of finance in catalyzing growth in economies with different ilk, we conclude that this study brings fresh evidence into the finance-growth relationship. This will in no small measure, stir further interest in revisiting previous conclusions drawn on this topical area. This is in addition to guiding policymakers in ensuring that the linearity and nonlinearity polarity of the finance-growth nexus are always factored-in while formulating policies relative to driving growth through financial deepening.

This study was done with a focus on the Nigerian economy, which arguably represents one of the largest economies in Africa. It is our firm belief that the use of Nigerian data contributes to a better understanding of the finance-growth nexus in an emerging economy with peculiarities that differ from those of the developed economies. Apparently, the results of this study can be employed for generalization in relation to economies like Nigeria not just within the African continent but also in other developing economies across the globe.

\section{REFERENCES}

Arize, A.C., 2017. A Convenient Method for The Estimation Of ARDL Parameters And Test Statistics: USA Trade Balance And Real Effective Exchange Rate Relation. International Review of Economics and Finance 50, 75-84 https://doi.org/10.1016/j.iref.2017.03.024

Arize, A.C., Kalu, E. U., Nkwor, N. N., 2018. Banks versus markets: Do they compete, complement or Co-evolve in the Nigerian financial system? An ARDL approach, Research in International Business and Finance, 45, 427-434 https://doi.org/10.1016/j.ribaf.2017.07.174

Aye, G. C., 2015. "Causality between Financial Deepening and Economic Growth in Nigeria: Evidence from a Bootstrap Rolling Window Approach" Journal of Economics, Business and Management, Vol. 3(8), pp. 795 - 801. https://doi.org/10.7763/JOEBM.2015.V3.288

Balago, G. S., 2014. Financial Sector Development and Economic Growth in Nigeria: An Empirical Investigation", International Journal of Finance and Accounting, 3(4), pp. 253 - 265. DOI: 10.5923/j.ijfa.20140304.05. 
Barajas, A., Chami, R., and Yoesfei, S. R., 2013. "The Finance and Growth Nexus Re-Examined: Do All Countries Benefit Equally?" IMF Working Paper, WP/13/130. https://doi.org/10.5089/9781484372104.001

CBN (Central Bank of Nigeria), 2015, Statistical Bulletin, Vol. 24, December, (CBN: Abuja).

Dahou, K., Omar, H. I., \& Pfister, M., 2009. Deepening African Financial Markets for Growth and Investment. NEPAD-OECD Africa Investment Initiative.

Fuller, W.A. (1976), Introduction to Statistical Time Series, New York: Wiley

Greenwood J., and Smith B.,1997. Financial markets in development, and the development of financial markets, Journal of Economic Dynamics and Control, 1997, vol. 21, issue 1, 145-181 https://doi.org/10.1016/0165-1889(95)00928-0

Grgorio, J. D., \& Guidotti, P. E., 1995. Financial Development and Economic growth. World Development, 23(2), 433-448. https://doi.org/10.1016/0305-750X(94)00132-I

Kalu, E. U., Nkwor, Nelson., \&. Onwumere, J.U.J.(2015).Measuring the Dynamics of Financial Deepening and Economic Growth in Nigeria, 1981 - 2013: Using Engel-Granger Residual Based Approach IOSR Journal of Economics and Finance (IOSR-JEF) e-ISSN: 2321-5933, p-ISSN: 2321-5925.Volume 6, Issue 6. Ver. I (Nov. - Dec. 2015), PP 82-89

Khan, M. S., \& Senhadji, A. S. (2000). Financial Development and Economic Growth: An Overview. IMF Working Paper, no.00/209. https://doi.org/10.5089/9781451874747.001

McKinnon, R., 1973. Money and Capital in Economic Development, Washington: The Brookings Institution.

Ndebbio, J. E. U., 2004. "Financial Deepening, Economic Growth and Development: Evidence from Selected Sub-Saharan
African Countries" AERC Research Paper 142, Nairobi: African Economic Research Consortium.

Nzotta, S. M., and Emeka J. O., 2009. "Financial Deepening and Economic Development of Nigeria: An empirical Investigation", African Journal of Accounting. Economic, Finance and Banking Research, Vol. 5(5), pp. 52 - 66.

Onwumere, J. U. J., Imo G. Ibe, Frank O. Ozoh and Oge M., 2012. "The impact of Financial Deepening on Economic Growth: Evidence from Nigeria", Research Journal of Finance and Accounting, Vol. 3(10), pp. $64-70$.

Pesaran, M.H., Shin, Y., Smith, R.J., 2001. Bounds testing approaches to the analysis of level relationships. J. Appl. Econometrics 16 (3), 289-326 https://doi.org/10.1002/jae.616

Phillips, P.C.B., and Perron, P., 1988. "Testing for Unit Roots in a Time Series Regression", Biometrika, 75, 335-346 https://doi.org/10.1093/biomet/75.2.335

Robinson, J., 1952. The Generalization of the General Theory and other Essays, New York: MacMillan: London.

Shaw, E. S., 1973. Financial Deepening in Economic Development, (New York: Oxford University Press).

Shin, Y., Yu, B., \& Greenwood-Nimmo, M., 2014. Modelling Asymmetric Cointegration and Dynamic Multipliers in an ARDL Framework. In: Horrace, W.C., Sickles, R.C. (eds), Festschrift in Honor of Peter Schmidt. Springer Science and Business Media, New York. https://doi.org/10.1007/978-1-4899-8008-3 9

Zivot, E. and Andrews, K. (1992), "Further Evidence On the Great Crash, The Oil Price Shock, and the Unit Root Hypothesis", Journal of Business and Economic Statistics, 10 (10), pp. $251-70$ https://doi.org/10.1080/07350015.1992.10509904

Received on 01-10-2019

DOI: https://doi.org/10.6000/1929-7092.2019.08.115

(c) 2019 Kalu et al.; Licensee Lifescience Global.

This is an open access article licensed under the terms of the Creative Commons Attribution Non-Commercial License (http://creativecommons.org/licenses/by-nc/3.0/) which permits unrestricted, non-commercial use, distribution and reproduction in any medium, provided the work is properly cited. 